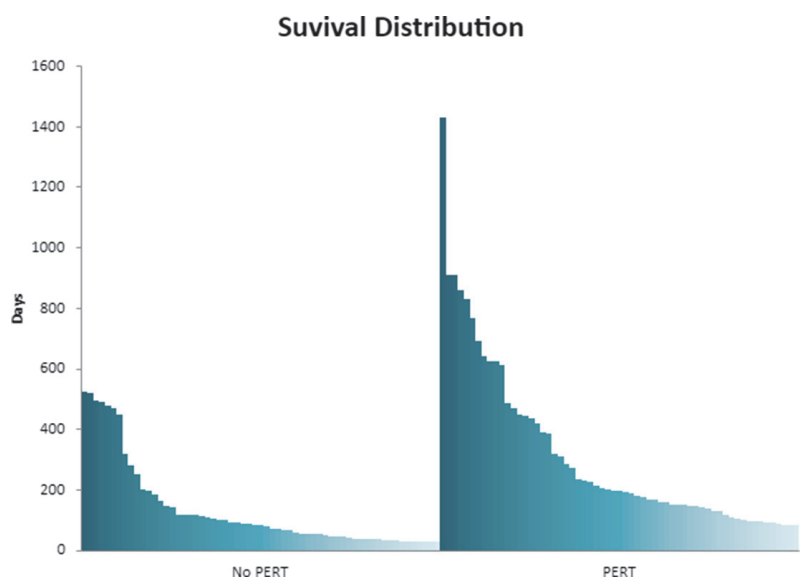

Abstract PTU-70 Figure 1

$(p=.0017)$ and were more likely to receive chemotherapy (33 patients vs 12 patients, $\mathrm{p}<.001)$ compared to the no PERT group. The PERT group had longer survival times (median survival 151 days vs 46 days, $\mathrm{p}<.001$, figure 1 ).

There was increased survival for patients treated with PERT when patients treated with chemotherapy were excluded (median survival of 98 days vs 37 days, $\mathrm{p}=.004$ ). Additionally, there was increased survival for those treated with PERT and chemotherapy compared to those treated with chemotherapy without PERT (226 days vs 101 days, $\mathrm{p}=.04$ ).

Sub-group analysis demonstrated statistically significant increased survival for patients treated with PERT with cancer of the pancreatic head (median survival of 165 days vs 44 days, $\mathrm{p}=.001$ ) and of the pancreatic body (median survival of 174 days vs 37 days, $\mathrm{p}=.001)$.

Conclusions This retrospective, pragmatic study of patients diagnosed with unresectable pancreatic cancer showed that less than half of patients were treated with PERT. PERT was associated with a clinically significant (approximately 3-fold) increase in survival regardless of whether chemotherapy was given. However, these results are likely to be confounded by selection bias given the higher percentage of patients in the no PERT group with more advanced disease and poorer performance status. We recommend offering all patients diagnosed with unresectable pancreatic cancer PERT.

\section{PTU-71 POST ERCP INDUCED PANCREATITIS: DOES PROPHYLACTIC PANCREATIC STENTING MAKE A DIFFERENCE?}

Brenavan Natarajan*, Bijan Yazdanian, Akash Jha, Alistair King, Mohammed Shariff, Anthony Leahy. Watford General Hospital, Watford, UK

\subsection{6/gutjnl-2021-BSG.273}

Introduction Post- ERCP Pancreatitis (PEP) is a significant complication of ERCP, especially in high risk rases or where there has been involvement of the pancreatic duct. Rectal NSAIDs and pancreatic duct stents are used to reduce the risk of PEP. It is not yet known if PD stents plus rectal NSAIDs reduce the risk of PEP more than rectal NSAIDs alone.

Methods We performed a retrospective analysis of 2028 ERCPs performed at a single large DGH centre in the UK to examine if PD stenting plus rectal NSAID significantly reduced the risk post procedure complications.

\begin{tabular}{|c|c|c|c|}
\hline & $\begin{array}{l}\text { No PD wire } \\
\text { or contrast }\end{array}$ & $\begin{array}{l}\text { PD wire or contrast } \\
\text { but no PD stent }\end{array}$ & $\begin{array}{l}\text { PD wire or contrast } \\
\text { and PD stent inserted }\end{array}$ \\
\hline Total number & 1469 & 348 & 211 \\
\hline Mean age in years & 69 & 67 & 64 \\
\hline Range in years & $16-101$ & $17-101$ & $19-94$ \\
\hline Male: Female ratio & $628: 841$ & 151:197 & $87: 124$ \\
\hline ASA Status & 1.48 & 1.40 & 1.80 \\
\hline Pancreatitis rate & $\begin{array}{l}36 / 1469 \\
(2.5 \%) \\
(p=0.01)\end{array}$ & $\begin{array}{l}15 / 348 \\
(4.3 \%) \\
(p=0.03)\end{array}$ & $\begin{array}{l}10 / 211 \\
(4.7 \%) \\
(p=0.03)\end{array}$ \\
\hline $\begin{array}{l}\text { Mean number of PD } \\
\text { contrast injections }\end{array}$ & $\mathrm{n} / \mathrm{a}$ & 0.55 & 0.64 \\
\hline $\begin{array}{l}\text { Mean number of PD } \\
\text { wire passes }\end{array}$ & $\mathrm{n} / \mathrm{a}$ & 1.87 & 2.85 \\
\hline $\begin{array}{l}\text { IV fluids administered } \\
\text { post procedure }\end{array}$ & $11 \%$ & $0 \%$ & $0 \%$ \\
\hline Rectal NSAID given & $36 / 36(100 \%)$ & $15 / 15(100 \%)$ & $10 / 10(100 \%)$ \\
\hline $\begin{array}{l}\text { Severity of } \\
\text { pancreatitis } \\
\text { (Modified Marshall } \\
\text { score) }\end{array}$ & 0.97 & $0.4(p=0.13)$ & $0.6(p=0.53)$ \\
\hline $\begin{array}{l}\text { Mean Length of stay } \\
\text { (days) }\end{array}$ & 7.7 & $6.9(p=0.70)$ & $5.5(p=0.11)$ \\
\hline ITU involvement & $4 / 36(11 \%)$ & $2 / 15(13 \%)$ & $0 / 10(0 \%)$ \\
\hline Deaths & $4 / 36(11 \%)$ & $1 / 15(6.7 \%)$ & $0 / 10(0 \%)$ \\
\hline
\end{tabular}

Results We found pancreatitis occurred in 3\% of ERCPs $(n=61)$. All patients had rectal NSAIDs administered at time of ERCP. We found PD involvement significantly increased the rate of PEP. We found that PD stenting did not significantly provide reduction in the severity of pancreatitis, measured by Modified Marshal or Atlanta scores, compared to those that had PD involvement without PD stent insertion or those without PD duct involvement. There was no significant difference in length of admission amongst groups.

Conclusions Our study further demonstrates that PD involvement at ERCP increases the rate of PEP. However, our study suggests PD stenting does not significantly provide reduction in rates of pancreatitis when used in combination with rectal NSAID therapy. In addition, there is an additional cost associated with PD stent placement plus the need for further follow-up if the PD stent does not spontaneously pass. We do reflect the number of pancreatitis cases in our cohort was small and that this was the experience from a single, large centre. We suggest further randomised controlled trials are required to prove the benefit of $\mathrm{PD}$ stent placement in combination with rectal NSAIDs over rectal NSAIDs alone in prevention of post-ERCP pancreatitis.

\section{PTU-72 OUTCOMES OF SURGERY FOR CHRONIC PANCREATITIS IN THE MANCHESTER SPECIALIST MULTI-DISCIPLINARY PANCREATITIS SERVICE}

Matthew Burrows*, Ala Elwasila, Ajith Siriwardena, Alistair Makin, Abubaker YM Ahmed. Manchester University Foundation Trust, Manchester, UK

\subsection{6/gutjnl-2021-BSG.274}

Introduction The management of chronic pancreatitis is complex. In Manchester, a multi-disciplinary approach to care has 